\title{
Factors Affecting Automatic Positive Airway Pressure Therapy Adherence in Patients Who had Completed the 3-Month Compliance Assessment for Korean National Health Insurance Coverage
}

\author{
Min Su Kim, MD, Min Gyu Kim, MD, Jae-yoon Kang, MD, Jae in Chung, MD, Yu Ju Seo, MD, \\ Soo-Kyoung Park, MD, PhD, Ki-Sang Rha, MD, PhD, Yong Min Kim, MD, PhD \\ Department of Otorhinolaryngology-Head and Neck Surgery, Research Institute for Medical Science, Chungnam National University School of Medicine, \\ Daejeon, Korea
}

\author{
Received: July 4, 2021 \\ Revised: September 1, 2021 \\ Accepted: September 9, 2021 \\ Correspondence \\ Yong Min Kim, MD, PhD \\ Department of Otorhinolaryngology- \\ Head and Neck Surgery, \\ Research Institute for Medical Science, \\ Chungnam National University \\ School of Medicine, \\ 282 Munhwa-ro, Jung-gu, \\ Daejeon 35015, Korea \\ Tel +82-42-280-7696 \\ Fax +82-42-253-4059 \\ E-mail entkym@cnu.ac.kr \\ ORCID \\ Min Su Kim \\ https://orcid.org/0000-0003-1850-1199 \\ Min Gyu Kim \\ https://orcid.org/0000-0001-6085-3687 \\ Jae-yoon Kang \\ https://orcid.org/0000-0003-0599-9493 \\ Jae in Chung \\ https://orcid.org/0000-0002-9847-3345 \\ Yu Ju Seo \\ https://orcid.org/0000-0003-3578-0505 \\ Soo-Kyoung Park \\ https://orcid.org/0000-0002-5163-536X \\ Ki-Sang Rha \\ https://orcid.org/0000-0001-9981-057X \\ Yong Min Kim \\ https://orcid.org/0000-0001-5414-8332
}

(c) This is an Open Access article distributed under the terms of the Creative Commons Attribution Non-Commercial License (https://creativecommons.org/licenses/by-nc/4.0) which permits unrestricted non-commercial use, distribution, and reproduction in any medium, provided the original work is properly cited.
Background and Objective The numbers of prescriptions for continuous positive airway pressure and automatic positive airway pressure (APAP) machines have increased dramatically since the Korean government changed national health insurance coverage. This study examined adherence to APAP therapy in patients with obstructive sleep apnea who completed the 3-month adaptation period required by the insurance service, and evaluated the factors predictive of good adherence.

Methods We retrospectively reviewed the medical records of a total of 315 patients who received APAP prescriptions between July 2018 and December 2019. After screening, 189 patients were analyzed. Patients were divided into an adherent (AD) group and a non-adherent (NAD) group based on 9 months' APAP adherence. Patient demographics, medical history, body mass index and pretreatment polysomnography results, as well as APAP therapy adherence-related variables, the 90th percentile pressure, residual apnea hypopnea status, and type of devices or managers were compared between the two groups.

Results We found mean usage times, mean pressures, days with $\geq 4$ hours of use a day, and 90th percentile pressures differed significantly between the $\mathrm{AD}$ and NAD groups. The device-related data at months 1 and 3 and 9 were similar. One type of device performed differently compared to the other devices, but this did not affect adherence.

Conclusions The mean pressure and 90th percentile pressure were the main determinants of adherence in patients who passed a 3-month compliance assessment conducted by the Korean National Institute of Health. The data on adherence at months 1, 3 and 9 were similar.

Sleep Med Res 2021;12(2):125-132

Keywords National health insurance; Obstructive; Patient adherence; Sleep apnea.

\section{INTRODUCTION}

Obstructive sleep apnea (OSA) is a potentially life-threatening disorder [1] characterized by repetitive (partial or complete) upper airway obstruction during sleep. This obstruction is frequently associated with arterial de-saturation, which disrupts the normal sleep architecture. OSA is often associated with a higher prevalence of cardiovascular disease [2-4], cognitive impairment $[5,6]$, and changes in personality and behavior [7-9], as well as an increased risk of traffic accidents [10,11].

Application of continuous positive airway pressure (CPAP) is considered the gold standard treatment for OSA [12-16]. Multiple studies have demonstrated that daily use of CPAP ma- 
chines is effective in reducing scores on the apnea-hypopnea index (AHI), decreasing daytime sleepiness and traffic accidents, and improving quality of life $[17,18]$. Despite the definitive advantages of OSA treatment, poor adherence remains a major cause of treatment failure among patients who receive a prescription for a CPAP machine. Therefore, for long-term CPAP use, it is important to determine the factors that predict good adherence. Although various attempts have been made to predict and identify the factors associated with short- and long-term compliance, the available data are diverse and conflicting [19-27].

In July 2018, the Korean government approved the coverage of polysomnography (PSG) and positive airway pressure (PAP) therapy under the national health insurance system. This was followed by an enormous increase in the numbers of prescriptions for CPAP and automatic PAP (APAP) machines. Specifically, the number of patients undergoing PSG increased fourfold and the number of patients using PAP devices increased 3.11-fold between 2018 and 2019 [28]. Few studies have evaluated adherence to APAP treatment among those for whom treatment was newly covered by health insurance, although some researchers predicted a potential improvement in adherence to PAP therapy [29]. To address this, we examined 9-month adherence to APAP therapy in OSA patients after completion of the 3-month adaptation period required by the Korean National Institute of Health (NIH), and evaluated the factors that predicted good adherence.

\section{METHODS}

\section{Subjects}

We obtained data from a total of 315 patients who had been diagnosed with OSA (AHI $\geq 5 / \mathrm{h}$ ) by a physician and were prescribed the use of an APAP machine between July 2018 and December 2019 at a single tertiary hospital. We retrospectively reviewed the medical records of the patients. We excluded patients with factors that could influence adherence to APAP therapy, such as severe nasal septal deviation; chronic rhinosinusitis; a previous history of nasal, palatal, or hypopharynx surgery; and severe cardiopulmonary conditions, as well as those who were not suitable for APAP therapy such as patients who required supplemental oxygen, with suspected hypoventilation, likely to have central apnea, with pressure intolerance, or diagnosed with chronic obstructive pulmonary disease. Patients who had failed to pass the 90-day adaptation period for Korean national insurance coverage were also excluded from the study. We finally analyzed data from 189 patients.

The study protocol was approved by the Institutional Review Board of Chungnam National University Hospital (CNUH 202101-010). However, as it was a retrospective review of medical charts, written informed consent was not obtained from each patient prior to the inclusion of their data in the study.

\section{Methods}

The patients were divided into two groups depending on whether they were adherent $(\mathrm{AD})$ or non-adherent (NAD) regarding APAP use at 9 months. Good adherence was defined as regular use of a PAP device for more than 4 hours/night for $>$ $70 \%$ of the recorded period. We reviewed patient demographics, medical history, body mass index (BMI; $\left.\mathrm{kg} / \mathrm{m}^{2}\right)$, pretreatment PSG results, and the results of four questionnaires (Pittsburgh Sleep Quality Index [PSQI], Epworth Sleepiness Scale [ESS], Beck Depression Inventory [BDI], and Beck Anxiety Inventory $[\mathrm{BAI}])$. During APAP therapy, follow-ups were conducted at 1, 3, and 9 months. Clinical symptoms, APAP-adherencerelated variables (number of hours of use per night, percentage of total days of APAP usage, and mean time of APAP usage), the 90th percentile pressure (P90), incidence of mask leakage, and residual AHI were assessed using data from the ventilator memory card. Four types of APAP devices (Philips, RESmart, ResMed, and $F \& P$ ) were used and managed by three different companies that were randomly allocated. APAP-adherence-related variables were assessed at 9 months after treatment initiation according to the device manager.

\section{Sleep Questionnaires}

\section{Pittsburgh Sleep Quality Index (PSQI)}

The PSQI was used to assess sleep quality. The questionnaire comprises 18 questions in seven categories (subjective sleep quality, sleep incubation period, sleep duration, sleep efficiency, degree of sleep disturbance, use of sleeping pills, and daytime activity disorders) [30]. Each item was scored from 0 to 3 to obtain a total score of 0 to 21 points, with higher scores indicating poorer sleep quality.

\section{Epworth Sleepiness Scale (ESS)}

The ESS was used to measure the degree of daytime sleepiness. Each item was scored from 0 to 3, and the total score ranged from 0 to 24 [31]. A higher score reflected a greater likelihood that the patient was sleepy in daily life. Daytime sleepiness was defined as present in cases with a total score of 11 or higher.

\section{Beck Depression Inventory (BDI) and Beck Anxiety Inventory (BAI)}

The BDI and BAI are questionnaires used to measure symptoms of depression and anxiety, respectively. We included these questionnaires in the analysis because previous studies have reported symptoms of depression in patients with OSA. Each questionnaire consists of 21 items, and each item is scored from 0 to 3 , resulting in a total score of $0-63$ points $[32,33]$. In the BDI, depressive symptoms are classified as minimal (0-13), mild (14$19)$, moderate (20-28), or severe (29-63), and in the BAI, anxiety is classified as minimal (0-7), mild (8-15), moderate (16$25)$, or severe (26-63). 


\section{Statistical Analysis}

The data are presented as means \pm standard deviation or as numbers of patients and percentages. Statistical significance was assessed mainly using the chi-square test or independent t-test, but one-way analysis of variance (ANOVA) was used to compare three or more items, with the Scheffe test used for post-hoc analysis. We used IBM SPSS software (version 19, SPSS Statistics; IBM Corp., Armonk, NY, USA) for all analyses, and a pvalue $<0.05$ was considered to indicate statistical significance.

\section{RESULTS}

\section{Demographics and APAP Mask Types According to Adherence Status}

We analyzed data from a total of 189 patients who completed the 90-day adaptation period. The patients were divided into $\mathrm{AD}$ group $(\mathrm{n}=123)$ and $\mathrm{NAD}$ group $(\mathrm{n}=66)$ according to the level of adherence to APAP device use at 9 months. The numbers (percentages) of male patients were $105(85.4 \%)$ in the $\mathrm{AD}$ group and $57(86.4 \%)$ in the NAD group. The median age was 49 years in the $\mathrm{AD}$ group and 52 years in the NAD group, and $\mathrm{BMI}$ values in the $\mathrm{AD}$ and $\mathrm{NAD}$ groups were $27.45 \pm 3.85$ and $27.81 \pm 3.94$, respectively. A nasal-type mask was used by 102 (82.9\%) patients in the $\mathrm{AD}$ group and 52 (78.8\%) patients in the NAD group, and a nasal pillow-type mask was used by 20
(16.3\%) patients in the $\mathrm{AD}$ group and 14 (21.2\%) patients in the NAD group. There was no significant difference in age, sex, mask type, or BMI between the $\mathrm{AD}$ and NAD groups (Table 1).

\section{APAP-Therapy-Related Data at Month 9 According to Adherence Status}

The mean device usage times, mean pressures, and numbers of days on which the device was used more than 4 hours a day (\%) in the $\mathrm{AD}$ and NAD groups were $331.25 \pm 87.56$ and $264.61 \pm$ $89.67,7.43 \pm 1.83$ and $5.80 \pm 1.68$, and $75.72 \pm 19.21$ and $43.81 \pm$ 17.30 , respectively. There were significant differences $(\mathrm{p}=0.001$ for all) between the two groups. The P90 also differed significantly ( $\mathrm{p}=0.001)$ between the two groups: $9.09 \pm 2.24$ in the $\mathrm{AD}$ group and $7.51 \pm 2.26$ in the NAD group. Residual AHI was present in $2.88 \pm 2.26$ patients in the $\mathrm{AD}$ group and $2.37 \pm 2.22$ patients in the NAD group, and there was no significant difference $(\mathrm{p}=0.30)$ between the two groups (Table 2$)$.

\section{PSG Parameters and Sleep Questionnaire Scores According to Adherence Status}

PSG data were also compared between the groups (Table 3). We found no significant differences between the $\mathrm{AD}$ and NAD groups in terms of the AHI ( $51.07 \pm 22.87$ vs. $44.97 \pm 22.86)$, rapid-eye-movement (REM) AHI (51.94 \pm 26.32 vs. $45.32 \pm$ 22.15), non-REM AHI ( $49.46 \pm 24.71$ vs. $44.65 \pm 24.59$ ), supine AHI (62.47 \pm 29.69 vs. $54.71 \pm 25.97)$, and non-supine AHI

Table 1. Automatic positive airway pressure user demographics and information

\begin{tabular}{|c|c|c|c|c|}
\hline & Study population $(\mathrm{n}=189)$ & $\mathrm{AD}$ group $(\mathrm{n}=123)$ & NAD group $(n=66)$ & p-value $\left(\chi^{2}\right)$ \\
\hline Sex & & & & $0.852(0.035)$ \\
\hline Male & 162 & $105(85.4)$ & $57(86.4)$ & \\
\hline Female & 27 & $18(14.6)$ & $9(13.6)$ & \\
\hline Age, yr (median range) & $51.5(17-86)$ & $49(17-81)$ & $52(18-86)$ & 0.287 \\
\hline BMI $\left(\mathrm{kg} / \mathrm{m}^{2}\right)$ & & $27.45 \pm 3.850$ & $27.81 \pm 3.949$ & 0.558 \\
\hline Mask type & & & & $0.545(1.212)$ \\
\hline Nasal & 154 & $102(82.9)$ & $52(78.8)$ & \\
\hline Nasal pillow & 34 & $20(16.3)$ & $14(21.2)$ & \\
\hline Oronasal & 1 & $1(0.8)$ & $0(0.0)$ & \\
\hline
\end{tabular}

Data are presented as $\mathrm{n}, \mathrm{n}(\%)$, or mean \pm standard deviation.

$\mathrm{AD}$, adherent; NAD, non-adherent; BMI, body mass index.

Table 2. Device data at the time of using automatic positive airway pressure for 9 months

\begin{tabular}{lccc}
\hline & AD group $(\mathrm{n}=123)$ & NAD group $(\mathrm{n}=66)$ & $\mathrm{p}$-value \\
\hline Mean usage time $(\mathrm{min})$ & $331.25 \pm 87.568$ & $264.61 \pm 89.673$ & 0.001 \\
Mean pressure $\left(\mathrm{cm} \mathrm{H}_{2} \mathrm{O}\right)$ & $7.43 \pm 1.830$ & $5.80 \pm 1.681$ & 0.001 \\
Days $\geq 4$ hours a day $(\%)$ & $75.72 \pm 19.218$ & $43.81 \pm 17.303$ & 0.001 \\
Residual AHI & $2.88 \pm 2.265$ & $2.37 \pm 2.221$ & 0.300 \\
$90 \%$ pressure $\left(\mathrm{cm} \mathrm{H}_{2} \mathrm{O}\right)$ & $9.09 \pm 2.246$ & $7.51 \pm 2.265$ & 0.001 \\
\hline
\end{tabular}

Data are presented as mean \pm standard deviation unless otherwise indicated.

$\mathrm{AD}$, adherent; $\mathrm{NAD}$, non-adherent; $\mathrm{AHI}$, apnea-hypopnea index. 
( $28.51 \pm 25.44$ vs. $26.16 \pm 27.13)$. Patients in each group were divided into mild, moderate, and severe OSA according to severity, and were compared the ratio. However, there were no significant differences $(\mathrm{p}=0.322)$ in ratio between two groups.

The minimal $\mathrm{O}_{2}$ saturation $\left(\min \mathrm{SpO}_{2}\right)$ values $(79.16 \pm 8.28$ vs. $81.18 \pm 7.76)$, sleep latencies $(11.76 \pm 13.31$ vs. $12.41 \pm 22.83)$, REM sleep latencies (122.83 \pm 72.14 vs. $128.62 \pm 75.27)$, wake time after sleep onset $(73.20 \pm 51.66$ vs. $78.62 \pm 57.91)$, and total sleep times ( $325.65 \pm 58.72$ vs. $324.47 \pm 81.57)$ also did not differ significantly between the two groups. In terms of sleep questionnaire scores, the PSQI ( $8.35 \pm 3.45$ vs. $8.22 \pm 3.26)$, ESS (9.91 \pm 5.51 vs. $9.23 \pm 5.31)$, BDI ( $8.12 \pm 7.53$ vs. $8.36 \pm 6.94)$, and BAI ( $21.02 \pm 12.62$ vs. $22.58 \pm 11.90)$ scores did not differ significantly between the two groups.

\section{APAP-Therapy-Related Data at 1 and 3 Months After the Korean NIH Compliance Assessment in the $\mathrm{AD}$ and NAD Groups}

Device-related data at 1 month and 3 months after the Korean NIH compliance assessment were also compared between the $\mathrm{AD}$ and NAD groups (Table 4). All parameters except residual AHI differed significantly between the two groups at each time point. The device-related data ( $\mathrm{AD}$ group vs. NAD group) at 1 month were as follows: mean usage time, $340.7 \pm 93.30 \mathrm{vs.}$ $299.9 \pm 102.76(\mathrm{p}=0.06)$; mean pressure, $7.3 \pm 1.98$ vs. $6.1 \pm 1.87$ $(\mathrm{p}=0.007)$, days on which the device was used for more than 4 hours, $81.9 \pm 17.62$ vs. $63.6 \pm 25.56$ ( $\mathrm{p}=0.003$ ); residual AHI, $3.49 \pm 2.7$ vs. $3.09 \pm 2.8$ ( $\mathrm{p}=0.525)$; and $\mathrm{P} 90,9.1 \pm 2.32$ vs. 7.84 $\pm 2.22(\mathrm{p}=0.013)$. The device-related data ( $\mathrm{AD}$ group vs. NAD group) at 3 months were as follows: mean usage time, $353.9 \pm$ 71.91 vs. $300.3 \pm 83.73$ ( $\mathrm{p}=0.001$ ); mean pressure, $7.4 \pm 1.76$ vs. $6.7 \pm 1.83$ ( $\mathrm{p}=0.017$ ); days on which the device was used for more than 4 hours, $79.2 \pm 15.86$ vs. $52.9 \pm 25.22(\mathrm{p}=0.001)$; residual AHI, $3.17 \pm 2.5$ vs. $2.83 \pm 2.3(\mathrm{p}=0.415)$; and P90, $9.2 \pm$ 2.16 vs. $8.41 \pm 2.17$ ( $\mathrm{p}=0.032$ ). Notably, the device-related data at months 1,3 and 9 were similar.

\section{Adherence Status According to APAP Device Manager and Type of APAP Device}

The patients were managed by three managers from different companies (managers A, B, and C). The number of patients managed by manager $\mathrm{C}$ was too small to compare with those handled by the other managers, so they were excluded from the comparison. The numbers (percentages) of patients managed by manager A were 81 (68.6\%) in the $\mathrm{AD}$ group and 39 (32.5\%) in the NAD group, whereas manager B managed 37 (61.7\%) patients in the $\mathrm{AD}$ group and $23(38.1 \%)$ patients in the NAD group (Table 5).

The patients used four types of devices (A, B, C, and D), but one device (device $\mathrm{D}$ ) was excluded because the number of patients who used it was small. Device A was used by 79 (66.9\%)

Table 3. Polysomnography data before automatic positive airway pressure treatment

\begin{tabular}{lccc}
\hline & AD group $(\mathrm{n}=123)$ & NAD group $(\mathrm{n}=66)$ & p-value \\
\hline AHI & $51.07 \pm 22.874$ & $44.97 \pm 22.863$ & 0.096 \\
Severity (n) & $5(4.06)$ & $3(4.54)$ & 0.322 \\
$\quad$ Mild (\%) & $21(17.07)$ & $16(24.24)$ & $47(71.21)$ \\
$\quad$ Moderate (\%) & $97(78.86)$ & $45.32 \pm 22.158$ & 0.084 \\
$\quad$ Severe (\%) & $51.94 \pm 26.321$ & $44.65 \pm 24.597$ & 0.203 \\
REM AHI & $49.46 \pm 24.711$ & $54.71 \pm 25.974$ & 0.076 \\
Non-REM AHI & $62.47 \pm 29.699$ & $26.16 \pm 27.133$ & 0.555 \\
Supine AHI & $28.51 \pm 25.446$ & $81.18 \pm 7.760$ & 0.104 \\
Non-Supine AHI & $79.16 \pm 8.280$ & $12.41 \pm 22.834$ & 0.605 \\
Min SpO (\%) & $11.76 \pm 13.315$ & $128.62 \pm 75.277$ & 0.806 \\
Sleep latency (min) & $122.83 \pm 72.142$ & $78.62 \pm 57.917$ & 0.510 \\
REM sleep latency (min) & $73.20 \pm 51.661$ & $324.47 \pm 81.571$ & 0.917 \\
WASO (min) & $325.65 \pm 58.719$ & $8.22 \pm 3.261$ & 0.834 \\
Total sleep time (min) & $8.35 \pm 3.459$ & $9.23 \pm 5.318$ & 0.444 \\
PSQI & $9.91 \pm 5.510$ & $8.36 \pm 6.942$ & 0.848 \\
ESS & $8.12 \pm 7.534$ & $22.58 \pm 11.908$ & 0.471 \\
BDI & $21.02 \pm 12.623$ & & \\
BAI & & & \\
\hline
\end{tabular}

Data are presented as mean \pm standard deviation or $\mathrm{n}(\%)$.

$\mathrm{AHI}$, apnea-hypopnea index; $\mathrm{AD}$, adherent; NAD, non-adherent; REM, rapid-eye-movement; min $\mathrm{SpO}_{2}$, minimal $\mathrm{O}_{2}$ saturation; WASO, wake time after sleep onset; PSQI, Pittsburgh Sleep Quality Index; ESS, Epworth Sleepiness Scale; BDI, Beck Depression Inventory; BAI, Beck Anxiety Inventory. 
Table 4. Device data at the time of using automatic positive airway pressure for 3 months and 1 month

\begin{tabular}{lccc}
\hline & AD group $(\mathrm{n}=123)$ & NAD group $(\mathrm{n}=66)$ & $\mathrm{p}$-value \\
\hline At first 3-month & $353.96 \pm 71.915$ & & 0.001 \\
Mean usage time $(\mathrm{min})$ & $7.42 \pm 1.767$ & $600.33 \pm 83.733$ & 0.017 \\
Mean pressure $\left(\mathrm{cm} \mathrm{H}_{2} \mathrm{O}\right)$ & $79.21 \pm 15.864$ & $52.94 \pm 25.220$ & 0.001 \\
Days $\geq$ 4 hours a day $(\%)$ & $3.17 \pm 2.506$ & $2.83 \pm 2.356$ & 0.415 \\
Residual AHI & $9.20 \pm 2.169$ & $8.41 \pm 2.177$ & 0.032 \\
$90 \%$ pressure $\left(\mathrm{cm} \mathrm{H}_{2} \mathrm{O}\right)$ & & & 0.060 \\
At first 1-month & $340.79 \pm 93.307$ & $299.92 \pm 102.765$ & 0.007 \\
Mean usage time $(\mathrm{min})$ & $7.39 \pm 1.982$ & $6.18 \pm 1.871$ & 0.003 \\
Mean pressure $\left(\mathrm{cm} \mathrm{H} \mathrm{H}_{2} \mathrm{O}\right)$ & $81.94 \pm 17.620$ & $63.64 \pm 25.564$ & 0.525 \\
Days $\geq 4$ hours a day $(\%)$ & $3.49 \pm 2.767$ & $3.09 \pm 2.873$ & 0.013 \\
Residual AHI & $9.15 \pm 2.322$ & $7.84 \pm 2.220$ & \\
90\% pressure $\left(\mathrm{cm} \mathrm{H} \mathrm{H}_{2} \mathrm{O}\right)$ & & & \\
\hline
\end{tabular}

Data are presented as mean \pm standard deviation unless otherwise indicated.

$\mathrm{AD}$, adherent; NAD, non-adherent; $\mathrm{AHI}$, apnea-hypopnea index.

Table 5. Comparison of adherence by manager and device

\begin{tabular}{lccc}
\hline & $\begin{array}{c}\text { AD group } \\
(\mathrm{n}=123)\end{array}$ & $\begin{array}{c}\text { NAD group } \\
(\mathrm{n}=66)\end{array}$ & p-value $\left(\chi^{2}\right)$ \\
\hline Manager* & & & $0.438(0.603)$ \\
Manager A & $81(67.5)$ & $39(32.5)$ & \\
Manager B & $37(61.7)$ & $23(38.3)$ & \\
Device $^{\dagger}$ & & & $0.391(1.879)$ \\
Device A & $79(66.9)$ & $39(33.1)$ & \\
Device B & $18(54.5)$ & $15(45.5)$ & \\
Device C & $21(67.7)$ & $10(32.3)$ & \\
\hline
\end{tabular}

Data are presented as $\mathrm{n}(\%)$ unless otherwise indicated.

*In the manager, 5 patients from $\mathrm{AD}$ group and 4 patients from NAD group are excluded as those belonging to manager $\mathrm{C}$; ${ }^{\dagger}$ In the device, 5 patients from $\mathrm{AD}$ group and 2 patients from NAD group are excluded as those belonging to device $\mathrm{D}$.

$\mathrm{AD}$, adherent; NAD, non-adherent.

patients in the $\mathrm{AD}$ group and $39(33.1 \%)$ patients in the $\mathrm{NAD}$ group, device $\mathrm{B}$ was used by 18 (54.5\%) patients in the $\mathrm{AD}$ group and $15(45.5 \%)$ patients in the NAD group, and device C was used by 21 (67.7\%) patients in the $\mathrm{AD}$ group and 10 (32.3\%) patients in the NAD group. There were no significant differences between the $\mathrm{AD}$ and NAD groups in terms of the manager responsible $(p=0.438)$ or the device type used $(p=0.391)($ Table 5$)$.

\section{APAP-Therapy-Related Data and PSG Parameters According to Type of APAP Device}

We assessed whether PAP device-related and PSG data differed depending on the device used (Table 6). Specifically, we compared PAP-device-related data such as the mean pressure, mean usage time, number of days on which the device was used for more than 4 hours (\%), residual AHI, P90, and PSG data such as the $\mathrm{AHI}$ and $\min \mathrm{SpO}_{2}$ (\%) according to device type.

The numbers of patients using devices A, B, and C were 118 ,
33, and 31, respectively. There were significant differences among device types in terms of the mean device pressure $(7.93 \pm 1.53$, $5.21 \pm 1.02$, and $7.70 \pm 1.90 ; \mathrm{p}<0.01)$, residual AHI $(3.76 \pm 2.35$, $1.54 \pm 1.16$, and $2.47 \pm 2.96 ; \mathrm{p}<0.01)$, and $\mathrm{P} 90(9.59 \pm 1.81$, $6.31 \pm 1.18$, and $10.13 \pm 2.22 ; \mathrm{p}<0.01)$. However, there were no significant differences among device types in terms of the mean usage time (304.39 $\pm 93.12,333.30 \pm 87.54$, and 328.52 \pm 96.05$)$ or percentage of days on which the device was used for more than 4 hours $(70.91 \pm 20.94,63.82 \pm 26.85$, and $69.92 \pm 21.76)$. In addition, we found no significant differences among device types in terms of PSG data such as the AHI $(47.09 \pm 23.62,49.37$ \pm 22.16 , and $54.57 \pm 22.85)$ or $\min \mathrm{SpO}_{2}(80.02 \pm 7.75,80.09 \pm$ 8.97 , and $79.32 \pm 8.94)$.

\section{DISCUSSION}

In this study, patients who passed the 3-month adherence assessment for Korean national insurance coverage were divided into the $\mathrm{AD}$ and NAD groups according to their adherence status at month 9. We enrolled only these patients because we speculated that during the initial assessment period, patients might have felt pressured to use the devices and that some artificial interventions by the device managers might have occurred. Therefore, we expected that evaluating adherence during the 6 months after completion of the initial assessment would more accurately reveal the factors affecting adherence.

We found no significant differences in sex, age, BMI, mask type used, PSG parameters such as the AHI and $\min \mathrm{SpO}_{2}$, or sleep questionnaire scores between the two groups. However, device-related parameters, such as the mean pressure and P90 $\left(\mathrm{cm} \mathrm{H}_{2} \mathrm{O}\right.$ ), were significantly higher in the $\mathrm{AD}$ group than in the NAD group ( $\mathrm{p}=0.001$ ) (Table 2). PAP adherence may increase in patients with severe OSA, because symptoms in patients with 
Table 6. Compare APAP, PSG data according to device

\begin{tabular}{|c|c|c|c|}
\hline & Device A $(n=118)$ & Device B $(n=33)$ & Device C $(n=31)$ \\
\hline \multicolumn{4}{|l|}{ APAP data } \\
\hline Mean usage time (min) & $304.39 \pm 93.127$ & $333.30 \pm 87.545$ & $328.52 \pm 96.059$ \\
\hline Mean pressure $\left(\mathrm{cm} \mathrm{H}_{2} \mathrm{O}\right)^{*}$ & $7.93 \pm 1.527$ & $5.21 \pm 1.023^{\mathrm{a}}$ & $7.70 \pm 1.896$ \\
\hline Days $\geq 4$ hours a day (\%) & $70.91 \pm 20.941$ & $63.82 \pm 26.859$ & $69.92 \pm 21.768$ \\
\hline Residual AHI* & $3.76 \pm 2.353$ & $1.54 \pm 1.162^{\mathrm{b}}$ & $2.47 \pm 2.962$ \\
\hline $90 \%$ pressure $\left(\mathrm{cm} \mathrm{H}_{2} \mathrm{O}\right)^{*}$ & $9.59 \pm 1.807$ & $6.31 \pm 1.178^{c}$ & $10.13 \pm 2.220$ \\
\hline \multicolumn{4}{|l|}{ PSG data } \\
\hline AHI & $47.09 \pm 23.626$ & $49.37 \pm 22.165$ & $54.57 \pm 22.857$ \\
\hline $\mathrm{Min} \mathrm{SpO}_{2}(\%)$ & $80.02 \pm 7.751$ & $80.09 \pm 8.977$ & $79.32 \pm 8.942$ \\
\hline
\end{tabular}

Data are presented as mean \pm standard deviation unless otherwise indicated.

${ }^{*} \mathrm{p}<0.01$; ${ }^{\mathrm{a}}$ Mean pressure: device B is statistically significantly lower for device A and device C, respectively; ${ }^{\mathrm{b}}$ Residual AHI: device B is statistically significantly lower for device A; ${ }^{9} 90 \%$ pressure: device B is statistically significantly lower for device A and device C, respectively.

APAP, automatic positive airway pressure; PSG, polysomnography; $\mathrm{AHI}$, apnea-hypopnea index; $\min \mathrm{SpO}_{2}$, minimal $\mathrm{O}_{2}$ saturation.

severe OSA are more likely to improve with PAP therapy compared to those in patients with mild OSA. In addition, APAP devices may not be able to detect events in OSA patients in the presence of an air leak and therefore, may respond in a suboptimal manner by lowering the therapeutic pressure [34,35]. A lower pressure may then increase the occurrence of residual events, which may result in the discontinuation of PAP device use. A previous study also emphasized the correlation between air leaks and therapeutic pressure [36]. In this study, however, such comparisons could not be made because the units for measuring air leakage were not comparable across the PAP devices from each company. Therefore, further research is needed regarding the correlation between therapeutic pressure and air leaks.

In the present study, the residual AHI did not differ significantly between the two groups $(\mathrm{p}=0.30)$, regardless of adherence status (Table 2). This result indicates that the therapeutic effects of APAP device use would be positive as long as the device worked, regardless of a patient's level of adherence. In addition, there were no significant differences between the two groups in terms of PSG parameters (Table 3). This result may be because our study was performed with patients who had already completed the 3-month assessment period.

Previous studies have reported close associations between OSA and scores on sleep questionnaires such as the BDI, BAI, and PSQI [37-39], whereas other studies found no significant associations [40]. We may not have found significant differences in BDI, BAI, ESS, and PSQI scores based on PAP therapy adherence status because the patients had already completed the 3-month assessment period.

The data for months 1 and 3 for the $\mathrm{AD}$ and NAD groups (Table 4) were similar to those for month 9, as shown in Table 2. These results indicate that adherence at months 1 and 3 was as important as that at month 9 .

In a previous study, the device manager was considered a significant factor affecting adherence [41]. Although we evaluated adherence according to device managers from different companies, our results indicate that the manager had no influence on PAP adherence (Table 5). Although the age, career status, and affiliated company of the device managers differed, we did not expect the company or the device manager to be critical factors. We also evaluated PAP therapy adherence and device-related data according to the type of device used (devices A, B, and C) (Tables 5 and 6). We found significant differences among device types in terms of the mean pressure, residual AHI, and P90, namely, that these were significantly lower for device $B$, although there were no significant differences between the $\mathrm{AD}$ and NAD groups according to device type. This result indicates that the device type was not a critical factor affecting PAP adherence but instead, that the lower values associated with device $B$ were characteristic of that specific PAP device.

To date, no comparative studies have examined the use of PAP devices before and after health insurance was made available to patients. In a previous Korean study (before the change in health insurance coverage), there were 25 patients in an $\mathrm{AD}$ group and 45 patients in an NAD group [42]. Although that study reported a difference between the $\mathrm{AD}$ and NAD groups in terms of ESS scores and $\min \mathrm{SpO}_{2}$ values, we found no significant differences in these variables. Again, this discrepancy was likely due to the different inclusion criteria used in our study.

The main limitation of this study is as follows: because PAP devices from multiple companies were used instead of devices from a single company, the measurement units for air leakage and therapeutic pressure levels (90\% or 95\%) differed across device types. Thus, we adjusted our comparisons (pressure levels of $90 \%$ and $95 \%$ were compared) or excluded data (e.g., incidences of large leaks) accordingly. It is well known that improvement of symptoms, such as excessive daytime sleepiness, are associated with good adherence of PAP therapy [19,21]. Therefore, we considered it necessary to check the improvement of symptoms before and after PAP therapy. However, we could not have all the 
participants in this study fill out ESS since our study was retrospective, which led to lack of ESS data after PAP therapy. Thus, it was difficult for us to compare the ESS and PAP adherence due to limited amount.

In conclusion, although various factors were associated with APAP therapy adherence, the mean pressure and P90 were the main determinants of adherence in patients who passed the 3-month compliance assessment for Korean national insurance coverage. The data on adherence at months 1,3 and 9 were similar.

\section{Availability of Data and Material}

All data generated or analyzed during the study are included in this published article.

\section{Author Contributions}

Conceptualization: Kim YM. Formal analysis: Kim MS. Investigation: Kim MS, Kim MG. Supervision: Park SK, Rha KS, Kim YM. Validation: Kang J, Seo YJ. Writing—original draft: Kim MS. Writing_review \& editing: Kim MS, Chung J.

\section{Conflicts of Interest}

The authors have no potential conflicts of interest to disclose.

\section{Funding Statement}

This work was supported by research fund of Chungnam National University.

\section{REFERENCES}

1. Young T, Palta M, Dempsey J, Skatrud J, Weber S, Badr S. The occurrence of sleep-disordered breathing among middle-aged adults. $N$ Engl J Med 1993;328:1230-5.

2. Jung JH, Kim SY, Yoon BK, Kang IG, Kim ST, Park KH. The consequence of cardiovascular sympathetic nervous system in obstructive sleep apnea. Korean J Otorhinolaryngol-Head Neck Surg 2008;51:1020-4.

3. Jean-Louis G, Zizi F, Clark LT, Brown CD, McFarlane SI. Obstructive sleep apnea and cardiovascular disease: role of the metabolic syndrome and its components. J Clin Sleep Med 2008;4:261-72.

4. Parish JM, Somers VK. Obstructive sleep apnea and cardiovascular disease. Mayo Clin Proc 2004;79:1036-46.

5. Gosselin N, Baril AA, Osorio RS, Kaminska M, Carrier J. Obstructive sleep apnea and the risk of cognitive decline in older adults. Am J Respir Crit Care Med 2019;199:142-8.

6. Musiek ES, Holtzman DM. Mechanisms linking circadian clocks, sleep, and neurodegeneration. Science 2016;354:1004-8.

7. Ekici A, Ekici M, Oğuztürk O, Karaboğa I, Cimen D, Senturk E. Personality profiles in patients with obstructive sleep apnea. Sleep Breath 2013;17:305-10.

8. Cayanan EA, Bartlett DJ, Chapman JL, Hoyos CM, Phillips CL, Grunstein RR. A review of psychosocial factors and personality in the treatment of obstructive sleep apnoea. Eur Respir Rev 2019;28:190005.

9. Lee JH, Shin WC, Na BS, Rhee HY, Choi HY, Kim SB, et al. Characteristics of emotion and personality in obstructive sleep apnea patients with insomnia symptoms: Analysis of Minnesota Multiphasic Personality Inventory. J Sleep Med 2015;12:59-63.

10. Karimi M, Hedner J, Häbel H, Nerman O, Grote L. Sleep apnea related risk of motor vehicle accidents is reduced by continuous positive airway pressure: Swedish Traffic Accident Registry data. Sleep 2015;38: 341-9.

11. Rodenstein D. Sleep apnea: traffic and occupational accidents - individual risks, socioeconomic and legal implications. Respiration 2009; 78:241-8.

12. Patil SP, Ayappa IA, Caples SM, Kimoff RJ, Patel SR, Harrod CG. Treat- ment of adult obstructive sleep apnea with positive airway pressure: an American Academy of Sleep Medicine clinical practice guideline. J Clin Sleep Med 2019;15:335-43.

13. Kakkar RK, Berry RB. Positive airway pressure treatment for obstructive sleep apnea. Chest 2007;132:1057-72.

14. Gay P, Weaver T, Loube D, Iber C. Evaluation of positive airway pressure treatment for sleep related breathing disorders in adults. Sleep 2006;29:381-401.

15. Kushida CA, Littner MR, Hirshkowitz M, Morgenthaler TI, Alessi CA, Bailey D, et al. Practice parameters for the use of continuous and bilevel positive airway pressure devices to treat adult patients with sleeprelated breathing disorders. Sleep 2006;29:375-80.

16. Sullivan CE, Issa FG, Berthon-Jones M, Eves L. Reversal of obstructive sleep apnoea by continuous positive airway pressure applied through the nares. Lancet 1981;1:862-5.

17. Gharibeh T, Mehra R. Obstructive sleep apnea syndrome: natural history, diagnosis, and emerging treatment options. Nat Sci Sleep 2010;2: 233-55.

18. Engleman HM, Kingshott RN, Wraith PK, Mackay TW, Deary IJ, Douglas NJ. Randomized placebo-controlled crossover trial of continuous positive airway pressure for mild sleep apnea/hypopnea syndrome. Am J Respir Crit Care Med 1999;159:461-7.

19. Kim HY, Jang MS. Improving compliance for continuous positive airway pressure compliance and possible influencing factors. Korean $J$ Otorhinolaryngol-Head Neck Surg 2014;57:7-14.

20. Kim HJ. Anatomical phenotypes of upper airway in OSA subjects and its influence on PAP adherence. J Clinical Otolaryngol 2019;30:20-4.

21. Mehrtash M, Bakker JP, Ayas N. Predictors of continuous positive airway pressure adherence in patients with obstructive sleep apnea. Lung 2019;197:115-21.

22. Aloia MS, Arnedt JT, Riggs RL, Hecht J, Borrelli B. Clinical management of poor adherence to CPAP: motivational enhancement. Behav Sleep Med 2004;2:205-22.

23. Broström A, Pakpour AH, Nilsen P, Gardner B, Ulander M. Promoting CPAP adherence in clinical practice: a survey of Swedish and Norwegian CPAP practitioners' beliefs and practices. J Sleep Res 2018;27: e12675.

24. Seo MY, Lee SH. Compliance with continuous positive airway pressure in patients with obstructive sleep apnea. Sleep Med Res 2020;11:714.

25. Guralnick AS, Balachandran JS, Szutenbach S, Adley K, Emami L, Mohammadi $\mathrm{M}$, et al. Educational video to improve CPAP use in patients with obstructive sleep apnoea at risk for poor adherence: a randomised controlled trial. Thorax 2017;72:1132-9.

26. van Zeller M, Severo M, Santos AC, Drummond M. 5-years APAP adherence in OSA patients - do first impressions matter? Respir Med 2013; 107:2046-52.

27. Kim JS, Kang YJ, Park CS, Hwang JH, Kim YJ. Clinical parameters related to the duration of automatic positive airway pressure titration. Sleep Med Res 2020;11:31-7.

28. Kim M, Baek H, Lee SY. Trends of clinical practice for obstructive sleep apnea following the change in the national health insurance coverage. J Sleep Med 2020;17:122-7.

29. Yoon HE, Jeon CJ, Hwang J, Lee HW, Jeon JY. Improved adherence to positive airway pressure treatment after covering National Health Insurance in patient with obstructive sleep apnea: a tertiary sleep center review. J Sleep Med 2021;18:22-8.

30. Buysse DJ, Reynolds CF 3rd, Monk TH, Berman SR, Kupfer DJ. The Pittsburgh Sleep Quality Index: a new instrument for psychiatric practice and research. Psychiatry Res 1989;28:193-213.

31. Johns MW. A new method for measuring daytime sleepiness: the Epworth sleepiness scale. Sleep 1991;14:540-5.

32. Beck AT, Ward CH, Mendelson M, Mock J, Erbaugh J. An inventory for measuring depression. Arch Gen Psychiatry 1961;4:561-71.

33. Beck AT, Epstein N, Brown G, Steer RA. An inventory for measuring 
clinical anxiety: psychometric properties. J Consult Clin Psychol 1988;56: 893-7.

34. Coller D, Stanley D, Parthasarathy S. Effect of air leak on the performance of auto-PAP devices: a bench study. Sleep Breath 2005;9:167-75.

35. Farré R, Montserrat JM, Rigau J, Trepat X, Pinto P, Navajas D. Response of automatic continuous positive airway pressure devices to different sleep breathing patterns: a bench study. Am J Respir Crit Care Med 2002;166:469-73.

36. Valentin A, Subramanian S, Quan SF, Berry RB, Parthasarathy S. Air leak is associated with poor adherence to autoPAP therapy. Sleep 2011; 34:801-6.

37. Li YY, Mazarakis T, Shen YC, Yang MC, Chang ET, Wang HM. Anxiety and depression are improved by continuous positive airway pressure treatments in obstructive sleep apnea. Int J Psychiatry Med 2016; 51:554-62.

38. Rezaeitalab F, Moharrari F, Saberi S, Asadpour H, Rezaeetalab F. The correlation of anxiety and depression with obstructive sleep apnea syndrome. J Res Med Sci 2014;19:205-10.

39. Han KH, Soh M, Ha JH, Ryu SH, Yu J, Park DH. The correlation between severity of sleep apnea, sleep and mood related scales, and activity during sleep in obstructive sleep apnea syndrome patients. Sleep Med Psychophysiol 2011;18:76-81.

40. Macey PM, Woo MA, Kumar R, Cross RL, Harper RM. Relationship between obstructive sleep apnea severity and sleep, depression and anxiety symptoms in newly-diagnosed patients. PLoS One 2010;5:e10211.

41. Kim SL, Kim J, Kim DS, Jo MG, Kim SD, Cho KS. Effect of doctor and device manager on adherence with positive airway pressure therapy in obstructive sleep apnea patients. J Rhinol 2018;25:26-31.

42. Kim MJ, Kim MJ, Bae SH, Park CH, Kim DK. Predictors of adherence with positive airway pressure treatment in patients with obstructive sleep apnea in Korean. J Rhinol 2015;22:89-95. 